\title{
Prevalence of dementia and Alzheimer's disease in elders of nursing homes and a senior center of Durango City, Mexico
} Cosme Alvarado-Esquivel ${ }^{* 1}$, Ana Berthina Hernández-Alvarado1, Rosa Oralia Tapia-Rodríguez ${ }^{2}$, Ángel Guerrero-Iturbe ${ }^{1}$, Karina RodríguezCorral $^{1}$ and Sergio Estrada Martínez ${ }^{1}$

Address: ${ }^{1}$ Facultad de Medicina, Universidad Juárez del Estado de Durango. Durango City, Mexico and ${ }^{2}$ Hospital Psiquiátrico "Miguel Vallebueno", Secretaría de Salud. Durango City, Mexico

Email: Cosme Alvarado-Esquivel* - alvaradocosme@yahoo.com; Ana Berthina Hernández-Alvarado - alvaradocosme@yahoo.com; Rosa Oralia Tapia-Rodríguez - ssadgo@dgo1.prodigy.net.mx; Ángel Guerrero-Iturbe - medicinaujed@terra.com.mx; Karina RodríguezCorral - alvaradocosme@yahoo.com; Sergio Estrada Martínez - alvaradocosme@yahoo.com

* Corresponding author

Published: 18 February 2004

BMC Psychiatry 2004, 4:3
Received: 08 August 2003

Accepted: 18 February 2004

This article is available from: http://www.biomedcentral.com/I47I-244X/4/3

(C) 2004 Alvarado-Esquivel et al; licensee BioMed Central Ltd. This is an Open Access article: verbatim copying and redistribution of this article are permitted in all media for any purpose, provided this notice is preserved along with the article's original URL.

\begin{abstract}
Background: Epidemiological reports about dementia and Alzheimer's disease (AD) in elderly people from developing countries are scarce. Therefore, we sought to determine the prevalences of dementia and $A D$ in a population of nursing home residents and senior center attendees of Durango City, Mexico, and to determine whether any socio-demographic characteristics from the subjects associated with dementia or AD exist.
\end{abstract}

Methods: One hundred and fifty-five residents of two nursing homes and 125 attendees of a senior center were examined for dementia and Alzheimer's disease. All subjects were tested by the minimental state examination, and those who scored twenty-four or less underwent psychiatric and neurological evaluations. Diagnosis of dementia, $A D$ and vascular dementia $(\mathrm{VaD})$ was based on the DSM-IV criteria. Socio-demographic characteristics from each participant were also obtained.

Results: Residents of nursing homes found to suffer from dementia were 25 out of 155 (16.1\%). Eighteen of them (1 $1.6 \%$ ) had AD, and seven (4.5\%) had $\mathrm{VaD}$. None of the attendees of the senior center suffered from dementia. Dementia (pooled $A D$ and $\mathrm{VaD}$ cases) correlated with white ethnicity $(\mathrm{OR}=3.2 ; 95 \% \mathrm{Cl}=1.28-8.3 \mathrm{I})$, and a history of unemployment $(\mathrm{OR}=6.46 ; 95 \% \mathrm{Cl}=$ I.42-25.97), while $A D$ correlated with journeymen occupations ( $O R=4.55 ; 95 \% \mathrm{Cl}=1.00-19.29)$.

Conclusion: Prevalence of dementia in residents of nursing homes found in this study is much lower than reported from more industrialized countries. $A D$ was more frequent than $\mathrm{VaD}$. Ethnicity and occupation showed effects on the prevalence figures. The prevalence of dementia found has implications for the optimum kind of health care that nursing homes should provide to their residents.

\section{Background}

Dementia in general and Alzheimer's disease (AD) in par- ticular affect elderly people all around the world [1-4]. Medicare costs for dementia are high and increase with 
severity of the disease and institutionalization [5]. The frequentness of dementia and $\mathrm{AD}$ vary substantially in different countries. In the United States, approximately $10 \%$ of the population older than sixty-five years of age suffers from dementia, with $\mathrm{AD}$ accounting for about two-thirds of the cases [2]. In a study of European population-based cohorts of persons sixty-five years and older, age-standardized prevalences of $6.4 \%$ for dementia and $4.4 \%$ for $\mathrm{AD}$ were found [6]. In contrast, elderly people of comparable age from an urban community in China, prevalences of $3.49 \%$ for dementia and $1.85 \%$ for $\mathrm{AD}$ have been reported [7]. Institutionalized elderly people have shown to have a higher frequency of dementia and $\mathrm{AD}$ than those found in the general population. For instance, in the United States, $26.4 \%$ of nursing home residents, identified in the 1995 Massachusetts Medicaid nursing home database, had a documented diagnosis of dementia [8]. Remarkably, dementia syndrome prevalence may be as high as $67.4 \%$ on admission to nursing homes [9] or as high as $72 \%$ later [10]. In Japan, in a neuropathological study, $39 \%$ of the autopsied nursing home residents had shown signs of dementia during their lives, and $\mathrm{AD}$ accounted for $34 \%$ of the cases [11]. Yet in special nursing homes, which may care for more highly impaired elders i.e. those with cognitive impairment and/or disturbed behaviors, by providing more staff time and more specialized staff assigments to residents than do traditional care units, the frequency of dementia is remarkably high. In a Japanese study, $27 \%$ and $55 \%$ of the residents in nursing homes and special nursing homes, respectively, showed dementia during life [12]. A number of risk factors for $A D$ have been reported including family history of dementia, marital status, history of major depression episodes [4], head trauma [13], chronic inflammatory reactions, oxidative and nitrosylative stresses, and high cholesterol levels [14]. In addition, the risk of suffering from $A D$ is greater among women $[1,7,15]$, and a number of genetic risk factors have been implicated that may increase the risk of developing $\mathrm{AD}$ [16]. There is a lack of information concerning the epidemiology of dementia and AD in elderly people of Mexico. Therefore, we conducted a cross-sectional, prospective, descriptive survey with a 2 phase screening design carried out over 2 years in order to determine the prevalences of dementia and $\mathrm{AD}$ in a population of nursing home residents and senior center attendees of Durango, a northern Mexican city. In addition, we sought to determine whether any socio-demographic characteristics of the subjects correlated with dementia or AD.

\section{Methods \\ Study population}

We have studied 280 elderly persons including 155 residents of 2 nursing homes and 125 attendees of a senior center. All elders were inhabitants of Durango City and represented the totality of residents and attendees of the two largest nursing homes and the only one senior center of Durango City. In this study, we considered a senior center as a place which elders use to attend courses such as handicraft, dancing, primary school, high school, singing, etc., and to organize local and national travels for pleasure. One nursing home takes care of women only while the other nursing home has a mixed population of women and men. Residents of the two nursing homes have the same level of care. Characteristics of facilities and the level of care, in both nursing homes and the senior center explored, are similar to those found in the majority of nursing homes and senior centers in Mexico. All 280 participants were studied from the year 2000 until 2002.

\section{Socio-demographic data, mini mental state examination, and neuropsychiatric evaluation}

This work was performed in two phases. Phase I was a screening survey carried out by trained psychologists who administered the validated Spanish version of the mini mental state examination (MMSE) $[17,18]$ to all 280 elders. We used the MMSE because it has proven to be an efficient, widely accepted instrument for the screening and assessment of cognitive impairment in the elderly [3,19-21]. We used a MMSE cut off point of 24 or less, thus subjects who had MMSE scores below 25 were recruited into the phase II study. Subjects with MMSE scores of 25 or more were not studied further. Although false negative subjects might exist in the study population, the likelihood that they were missed for further evaluation is low since a high MMSE cut off point was used.

All nursing home residents and senior center attendees were allowed to be studied at any time. Although some elders died during the 2 years of the screening period, we were able to study them all before they died. Therefore, none of the elders was excluded from the study. Since all subjects were screened, response bias and length-based sampling bias were avoided.

Socio-demographic data including age, gender, birth place, ethnic group, marital status, schooling, occupation during their productive age, socioeconomic level, history of alcohol use, history of smoking, and history of drug use from all 280 subjects studied were obtained [see Additional file 1]. This data was obtained during the screening stage, and of this data such as age, history of alcohol, of drug use, etc were verified during stage II. In a few cases, information from informants was used. Socioeconomic level was evaluated by using the Bronfman criteria [22]. Briefly, six socioeconomic variables were evaluated: number of persons in the house, number of rooms in the house, floor material of the house, availability of potable water, presence and type of plumbing in the house, and educational level of the head of the family. In nursing 
home residents, data corresponded to that found in the house where the person lived prior to the nursing home.

Phase II involved the assesment for dementia by a neurologist and a psychiatrist of all subjects who scored 24 or less in the MMSE. The diagnosis of dementia and $\mathrm{AD}$ was performed through clinical interview, and was based on the Diagnostic and Statistical Manual of Mental Disorders (DSM-IV) criteria [23]. Laboratory tests (complete blood count, electrolytes, glucose, calcium and TSH), medical record examinations, and information from informants were used to support the diagnosis. The diagnosis of $\mathrm{VaD}$ was determined by clinical examination, and was based on the DSM-IV criteria [23].

\section{Statistical Analysis}

Results were analyzed with the aid of the software Epi Info 6 . For age comparison among the groups, the $t$ student test was used. To assess the association between the characteristics of the subjects and the disease, the crude odds ratio with a $95 \%$ exact confidence interval was used. We calculated the exact confidence interval because the cell value (number of cases) was less than 5 in some comparisons. Odds ratio is the ratio between the probability of having disease among those exposed and the probability of having the disease among those not exposed [24]. Odds ratio was used because it is an important instrument as a measure of association [25]. Since the number of cases were too low, we did not perform multivariate analysis for age and gender adjustment. In addition, comparison of the frequencies between groups was performed by the $\chi^{2}$ test. A level of $P<0.05$ was considered significant.

\section{Results \\ Socio-demographic data}

Of the 155 residents of the 2 nursing homes studied, 110 were women and 45 were men. The mean age was 72.5 years (range: 61 to 99 years). A low socioeconomic status was found in eighty-six participants $(55.5 \%)$, a medium status in sixty-three $(40.6 \%)$, and a high status in six (3.9\%). Most people studied $(\mathrm{n}=100)$ were mestizos (people of mixed race i.e. Mexican Indian mixed with European and/or African people), fifty-five were white. Their occupations were: fifty-three housewives, ten retired, forty-one employees, nine professionals, twentytwo journeymen, five businessmen, and fifteen had a history of unemployment. Their marital status included twenty-four married (15.5\%), sixty-two widowed $(40.0 \%)$, sixty-six never married $(42.6 \%)$, and three divorced (1.9\%). Most of these participants (84.5\%) were born in Durango State, and the rest in other Mexican states $(15.5 \%)$. Fifty two participants $(33.5 \%)$ had a history of alcohol use, and thirty-four had a history of smoking $(21.9 \%)$. None of these participants had a history of drug use.
With respect to the 125 attendees of the senior center studied, 103 were women and 22 were men. The mean age was 69.0 years (range: 50 to 88 years). A low socioeconomic status was found in sixty-seven of these participants $(53.6 \%)$, a medium status in fifty-five $(44.0 \%)$, and a high status in three $(2.4 \%)$. Most people studied $(n=83)$ were mestizos, followed by whites $(n=41)$, and indigenous ( $n$ $=1$ ). Their occupations were: eighty-four housewives, seventeen retired, four employees, eight professionals, seven journeymen, four businessmen, and one had a history of unemployment. Their marital status included forty-one married $(32.8 \%)$, sixty widowed $(48.0 \%)$, nineteen never married (15.2\%), and five divorced (4.0\%). Most of the participants (66.4\%) were born in Durango State, and the rest in other Mexican states $(32.8 \%)$ or abroad $(0.8 \%)$. Twenty seven participants $(21.6 \%)$ had a history of alcohol use, and eight had a history of smoking (6.4\%). None of these participants had a history of drug use.

\section{Mini mental state examination and neuropsychiatry}

Of the 155 residents of the 2 nursing homes studied, 102 (65.8\%) showed lower MMSE grades than the cut off point. All 102 individuals with MMSE grades below the cut off point were further evaluated by the physician team. Twenty-five individuals were found to suffer from dementia $(16.1 \%)$. The causes of dementia were as follows: eighteen out of the twenty-five demented subjects $(11.6 \%)$ had $\mathrm{AD}$, and seven $(4.5 \%)$ had $\mathrm{VaD}$ dementia. There was consensus of diagnosis in every case by the neuropsychiatry team. Table 1 shows a summary of the MMSE and clinical results in nursing home residents.

With respect to the 125 attendees of the senior center studied, $30(24.0 \%)$ showed MMSE grades below the cut off point. All thirty subjects with low MMSE grades were also further evaluated by the physician team. None of the thirty subjects suffered from dementia. There was consensus of diagnosis in every case by the neuropsychiatry team.

As seen in Table 2, two socio-demographic characteristics of the elderly people studied were correlated with dementia (pooled $\mathrm{AD}$ and $\mathrm{VaD}$ cases): white ethnicity $(\mathrm{OR}=3.2$; $95 \% \mathrm{CI}=1.28-8.31)$, and history of unemployment (OR $=6.46 ; 95 \% \mathrm{CI}=1.42-25.97)$. Similarly, as seen in Table $3, \mathrm{AD}$ correlated with journeyman occupations $(\mathrm{OR}=$ $4.55 ; 95 \% \mathrm{CI}=1.00-19.29$ ).

\section{Discussion}

Studies on the prevalence of dementia and AD are encouraged. The results of such studies are useful to estimate the psychiatric and neurological needs of the population $[8,26,27]$. The overall prevalence of dementia and $\mathrm{AD}$ found in this study is comparable with those reported in elders from other countries $[2,3,28]$. The frequencies of dementia and $\mathrm{AD}$ were significantly higher in residents of 
Table I: Summary of the Mini-Mental State Examination (MMSE) and clinical results in residents of nursing homes.

\begin{tabular}{|c|c|c|c|c|c|}
\hline Age group & $\begin{array}{l}\text { Subjects tested with } \\
\text { MMSE }\end{array}$ & $\begin{array}{c}\text { Subjects with grades } \\
\text { below the } 25 \text { MMSE } \\
\text { cut off point }\end{array}$ & $\begin{array}{c}\text { Patients with } \\
\text { dementia (pooled } \\
\text { cases) }\end{array}$ & Patients with $A D^{a}$ & Patients with $\mathrm{VaDb}$ \\
\hline $5 I-64$ & 4 & $2(50.0 \%)$ & I (25.0\%) & I (25.0\%) & $0(0.0 \%)$ \\
\hline $65-74$ & 26 & $14(53.8 \%)$ & $3(11.5 \%)$ & I $(3.8 \%)$ & $2(7.7 \%)$ \\
\hline $75-84$ & 72 & $49(68.1 \%)$ & $10(13.9 \%)$ & $8(11.1 \%)$ & $2(2.8 \%)$ \\
\hline $85-94$ & 46 & $32(69.6 \%)$ & $8(17.4 \%)$ & 7 (I5.2\%) & I (2.2\%) \\
\hline $95-99$ & 7 & 5 (7I.4\%) & $3(42.9 \%)$ & $\mathrm{I}(14.3 \%)$ & $2(28.6 \%)$ \\
\hline Total (\%) & 155 & $102(65.8 \%)$ & $25(16.1 \%)$ & $18(11.6 \%)$ & $7(4.5 \%)$ \\
\hline
\end{tabular}

aAD: Alzheimer's disease. bVaD: Vascular dementia.

Table 2: Comparison of characteristics of the patients with dementia (pooled cases) and the elders without dementia.

\begin{tabular}{|c|c|c|c|c|}
\hline $\begin{array}{l}\text { Socio-demographic } \\
\text { Characteristics }\end{array}$ & $\begin{array}{c}\text { Persons with Dementia } \mathrm{n}= \\
25(\%)\end{array}$ & $\begin{array}{l}\text { Persons without dementia } \\
\qquad \mathrm{n}=255(\%)\end{array}$ & $\mathrm{OR}^{\mathrm{a}}$ & $95 \% \mathrm{Cl}^{\mathrm{b}}$ \\
\hline \multicolumn{5}{|l|}{ Gender } \\
\hline Female & 21 (84.0\%) & $192(75.3 \%)$ & 1.72 & $0.55-7.15$ \\
\hline Male & $4(16.0 \%)$ & $63(24.3 \%)$ & & \\
\hline \multicolumn{5}{|l|}{ Place of birth } \\
\hline Durango State & 21 (84.0\%) & $193(75.7 \%)$ & 1.69 & $0.54-7.00$ \\
\hline $\begin{array}{l}\text { Other Mexican states or } \\
\text { abroadc }\end{array}$ & $4(16.0 \%)$ & $62(24.3 \%)$ & & \\
\hline \multicolumn{5}{|l|}{ Socioeconomic level } \\
\hline Low & $14(56.0 \%)$ & 139 (54.5\%) & & \\
\hline Medium & $10(40.0 \%)$ & $108(42.4 \%)$ & 0.92 & $0.35-2.33$ \\
\hline High & I (4.0\%) & $8(3.1 \%)$ & 1.24 & $0.03-10.48$ \\
\hline \multicolumn{5}{|l|}{ Ethnic group } \\
\hline Mestizo & $10(40.0 \%)$ & $173(67.8 \%)$ & & \\
\hline White & $15(60.0 \%)$ & $81(31.8 \%)$ & 3.2 & $|.28-8.3|$ \\
\hline Indigenous & $0(0.0 \%)$ & I (0.4\%) & & \\
\hline \multicolumn{5}{|l|}{ Marital Status } \\
\hline Married & $4(16.0 \%)$ & 61 (23.9\%) & & \\
\hline Widowed & $7(28.0 \%)$ & $115(45.1 \%)$ & 0.93 & $0.23-4.50$ \\
\hline Never married & $14(56.0 \%)$ & $71(27.8 \%)$ & 3.01 & $0.88-13.12$ \\
\hline Divorced & $0(0.0 \%)$ & $8(31.4 \%)$ & & \\
\hline \multicolumn{5}{|l|}{ Occupation (historical) } \\
\hline Housewife & $9(36.0 \%)$ & $128(50.2 \%)$ & & \\
\hline Retired & $2(8.0 \%)$ & $25(9.8 \%)$ & 1.14 & $0.11-5.98$ \\
\hline Employee & $2(8.0 \%)$ & 43 (16.9\%) & 0.66 & $0.07-3.38$ \\
\hline Professional & $2(8.0 \%)$ & $15(5.9 \%)$ & 1.9 & $0.18-10.44$ \\
\hline Journeyman & $5(20.0 \%)$ & 24 (9.4\%) & 2.96 & $0.7 I-10.82$ \\
\hline Businessman & $0(0.0 \%)$ & $9(3.5 \%)$ & & \\
\hline Unemployed & $5(20.0 \%)$ & II (4.3\%) & 6.46 & $1.42-25.97$ \\
\hline \multicolumn{5}{|l|}{ History of alcohol use } \\
\hline Yes & $6(24.0 \%)$ & $73(28.6 \%)$ & 0.79 & $0.25-2.16$ \\
\hline No & 19 (76.0\%) & $182(7 \mid .4 \%)$ & & \\
\hline \multicolumn{5}{|l|}{ History of smoking } \\
\hline Yes & $3(12.0 \%)$ & 39 (I5.3\%) & 0.76 & $0.14-2.70$ \\
\hline No & $22(88.0 \%)$ & $216(84.7 \%)$ & & \\
\hline
\end{tabular}

aOR: Odds ratio. ${ }^{\mathrm{b}} \mathrm{Cl}$ : Confidence interval. Includes I subject from the United States with Mexican ancestry. 
Table 3: Comparison of characteristics of the patients with Alzheimer's disease (AD) and the elders without AD.

\begin{tabular}{|c|c|c|c|c|}
\hline $\begin{array}{l}\text { Socio-demographic } \\
\text { characteristics }\end{array}$ & Persons with AD $n=18(\%)$ & $\begin{array}{c}\text { Persons without } A D n= \\
262(\%)\end{array}$ & $\mathrm{OR}^{\mathrm{a}}$ & $95 \% \mathrm{Cl}^{\mathrm{b}}$ \\
\hline \multicolumn{5}{|l|}{ Gender } \\
\hline Female & 15 (83.3\%) & $198(75.6 \%)$ & 1.62 & $0.44-8.97$ \\
\hline Male & $3(16.7 \%)$ & $64(24.4 \%)$ & & \\
\hline \multicolumn{5}{|l|}{ Place of birth } \\
\hline Durango State & 15 (83.3\%) & 199 (76.0\%) & 1.58 & $0.43-8.79$ \\
\hline $\begin{array}{l}\text { Other Mexican states or } \\
\text { abroadc }\end{array}$ & $3(16.7 \%)$ & $63(24.0 \%)$ & & \\
\hline \multicolumn{5}{|l|}{ Socioeconomic level } \\
\hline Low & $11(61.1 \%)$ & $142(54.2 \%)$ & & \\
\hline Medium & $6(33.3 \%)$ & $112(42.7 \%)$ & 0.69 & $0.20-2.12$ \\
\hline High & I $(5.6 \%)$ & $8(3.1 \%)$ & 1.61 & $0.03-14.06$ \\
\hline \multicolumn{5}{|l|}{ Ethnic group } \\
\hline Mestizo & $9(50.0 \%)$ & $174(66.4 \%)$ & & \\
\hline White & $9(50.0 \%)$ & $87(33.2 \%)$ & 2 & $0.67-5.90$ \\
\hline Indigenous & $0(0.0 \%)$ & I $(0.4 \%)$ & & \\
\hline \multicolumn{5}{|l|}{ Marital Status } \\
\hline Married & $2(11.1 \%)$ & $63(24.0 \%)$ & & \\
\hline Widowed & $5(27.8 \%)$ & $117(44.7 \%)$ & 1.35 & $0.21-14.50$ \\
\hline Never married & $11(61.1 \%)$ & $74(28.2 \%)$ & 4.68 & $0.96-44.66$ \\
\hline Divorced & $0(0.0 \%)$ & $8(3.1 \%)$ & & \\
\hline \multicolumn{5}{|l|}{ Occupation (historical) } \\
\hline Housewife & $6(33.3 \%)$ & $|3|(50.0 \%)$ & & \\
\hline Retired & $2(11.1 \%)$ & $25(9.5 \%)$ & 1.75 & $0.16-10.47$ \\
\hline Employee & I (5.6\%) & 44 (16.8\%) & 0.5 & $0.01-4.28$ \\
\hline Professional & I (5.6\%) & $16(6.1 \%)$ & 1.36 & $0.03-12.40$ \\
\hline Journeyman & $5(27.7 \%)$ & $24(9.2 \%)$ & 4.55 & $1.00-19.29$ \\
\hline Businessman & $0(0.0 \%)$ & $9(3.4 \%)$ & & \\
\hline Unemployed & $3(16.7 \%)$ & $13(5.0 \%)$ & 5.04 & $0.72-26.73$ \\
\hline \multicolumn{5}{|l|}{ History of alcohol use } \\
\hline Yes & $3(16.7 \%)$ & $76(29.0 \%)$ & 0.49 & $0.09-1.81$ \\
\hline No & $15(83.3 \%)$ & 186 (71.0\%) & & \\
\hline \multicolumn{5}{|l|}{ History of smoking } \\
\hline Yes & I (5.6\%) & 41 (15.6\%) & 0.32 & $0.01-2.14$ \\
\hline No & $17(94.4 \%)$ & 221 (84.4\%) & & \\
\hline
\end{tabular}

aOR: Odds ratio. ${ }^{\mathrm{b}} \mathrm{Cl}$ : Confidence interval. cIncludes I subject from the United States with Mexican ancestry.

nursing homes $(16.1 \%$ and $11.6 \%$, respectively) than those found in attendees of the senior center $(0 \%$ and $0 \%$, $\mathrm{p}<0.0001$ and $\mathrm{p}<0.001$, respectively). The prevalences of dementia and $\mathrm{AD}$ in residents of the nursing homes found in this study are lower than those reported in the United States [8] and Japan [11,12]. In contrast, our prevalences of dementia and $\mathrm{AD}$ are higher that those reported in France [3]. It is not clear why the residents of the nursing homes showed a higher frequency of dementia than the attendees of the senior center. There are no admission policies in the nursing homes and the senior center that reject demented subjects. Nevertheless, attendees of the senior center had more stringent behavioral rules for permanency than residents of the nursing homes. Therefore, exclusion of some subjects with psychiatric illnesses might explain the lower prevalences found in the senior center. In addition, all attendees of the senior center had social interaction and intellectual stimulation whereas residents of the nursing homes did not. These factors could influence the frequency of dementia as reported by other authors [29,30]. Similar age between the senior center attendees and the nursing home residents was observed $(p>0.5)$. Since white ethnicity and history of unemployment were associated with dementia (all causes), we compared the frequency of these characteristics among the groups. The frequency of white ethnicity was significantly higher in nursing home residents than that found in attendees of the senior center $(51.6 \%$ vs $32.8 \%, \mathrm{p}<0.01)$. The association between white ethnicity and dementia observed in this study conflicts with those reported by Gurland [31] and Weintraub [32] that found higher frequencies of dementia in Latino and African- 
American groups than in whites. Similarly, the frequency of a history of unemployment was significantly higher in nursing home residents than the one observed in the senior center attendees $(6.5 \%$ vs $0.8 \%, \mathrm{p}<0.05)$. The association between dementia and unemployment found in this study agrees with data reported by Li [33]. It is not clear why unemployment relates to dementia, however, associated factors such as illnesses might contribute and this observation deserves further study. Remarkably, AD was associated with a history of journeyman occupations $(\mathrm{OR}=4.55 ; 95 \% \mathrm{CI}=1.00-19.29)$. To the best of our knowledge, this association has not been reported elsewhere. Nevertheless, this observation must be taken with care, since a low educational level was present with most journeymen. Other characteristics such as never married status $[34,35]$, reported to be related to $\mathrm{AD}$, and alcohol consumption [36] that may reduce the risk for AD were also analyzed. There were more never married subjects in the nursing homes than in the senior center (50.3 vs $15.2 \%, \mathrm{p}<0.0000001)$. In addition, we observed a higher frequency of never married subjects in the group of $\mathrm{AD}$ patients $(61.1 \%)$ than in the group of subjects without AD $(28.2 \%)$, and these results agree with data reported by Kristjansson [34] and Helmer [35]. However, the difference found in our study was not statistically significant $(\mathrm{OR}=4.68 ; 95 \% \mathrm{CI}=0.96-44.66)$. Never married elders seem to need more support than married elders who had family, this may explain why we found a higher frequency of never married elders in the nursing homes than in the senior center. History of alcohol use was equally distributed among residents and attendees, and among $\mathrm{AD}$ patients and non $\mathrm{AD}$ subjects in our study. This latter result agrees with a previous report [36], but conflicts with data reported by Lindsay [38] and Ruitenberg [36], since they found that alcohol consumption was associated with a reduced risk of $\mathrm{AD}$. Although the frequency of smoking was low, we observed a higher frequency of smoking in males than in females. Nevertheless, we did not find any positive or negative association between smoking and $\mathrm{AD}$ in our elderly population study. Other authors have shown similar results $[38,39]$. The most common cause of dementia in our study population was $\mathrm{AD}(72 \%)$. This finding is comparable with those findings reported in India [1] and France [40], but our frequency is higher than those reported in Japanese [12] and American-Chinese populations [41]. In the elderly people studied, $\mathrm{AD}$ was more frequently observed in women than in men (although not statistically significant). This finding agrees with previous observations that $\mathrm{AD}$ is more common in females $[1,7,15]$.

Characteristics of facilities and level of care of the nursing homes and the senior center of Durango are similar to those found in nursing homes and senior centers of other Mexican states. Results of this study may reflect, although to a limited extent, the frequencies of dementia and $\mathrm{AD}$ in elders of nursing homes and senior centers of Mexico; however, further studies should be conducted in order to determine the national magnitude of dementia as a public health problem in the elderly people of Mexico. The prevalence of dementia among the nursing home residents found in this study has implications for health care provision in nursing home residents, and resource implications for those responsible for publicly funded care. Similarly, the study identified factors to consider that may be useful when identifying subjects at risk for dementia.

\section{Conclusions}

We concluded that prevalences of dementia and $\mathrm{AD}$ in elderly people from Durango, Mexico are comparable to those reported in developed countries. $\mathrm{AD}$ was the most frequent cause of dementia followed by VaD. Dementia (pooled $\mathrm{AD}$ and $\mathrm{VaD}$ cases) correlated with white ethnicity, and a history of unemployment. Similarly, AD correlated with journeyman occupations.

\section{Competing interests}

None declared.

\section{Authors' contributions}

CAE conceived and designed the study protocol, participated in the coordination and management of the study, and wrote the manuscript. ABHA applied the questionnaires, and performed the data analysis. ROTR performed the clinical evaluation of the elders. AGI performed the clinical evaluation of the elders. KRC applied the questionnaires, and performed the data analysis. SEM performed the statistical analysis of the data.

\section{Acknowledgements}

The excellent assistance of Miss Maria del Rosario Alonso Almeida is greatly appreciated.

\section{References}

I. Vas CJ, Pinto C, Panikker D, Noronha S, Deshpande N, Kulkarni L, Sachdeva S: Prevalence of dementia in an urban Indian population. Int Psychogeriatr 2001, I 3:439-450.

2. Hendrie HC: Epidemiology of dementia and Alzheimer's disease. Am J Geriatr Psychiatry I998, 6(SuppI I):S3-I8.

3. Obadia Y, Rotily M, Degrand-Guillaud A, Guelain J, Ceccaldi M, Severo $C$ et al.: The PREMAP Study: prevalence and risk factors of dementia and clinically diagnosed Alzheimer's disease in Provence, France. Prevalence of Alzheimer's Disease in Provence. Eur J Epidemiol 1997, I3:247-253.

4. Tsolaki M, Fountoulakis K, Chantzi E, Kazis A: Risk factors for clinically diagnosed Alzheimer's disease: a case-control study of a Greek population. Int Psychogeriatr 1997, 9:327-4I.

5. Scuvee-Moreau J, Kurz X, Dresse A, National Dementia Economic Study Group: The economic impact of dementia in Belgium: results of the National Dementia Economic Study (NADES). Acta Neurol Belg 2002, I 02: I04-I3.

6. Lobo A, Launer LJ, Fratiglioni L, Andersen K, Di Carlo A, Breteler MM et al: Prevalence of dementia and major subtypes in Europe: A collaborative study of population-based cohorts. Neurologic Diseases in the Elderly Research Group. Neurology 2000, 54(Suppl 5):S4-9. 
7. Wang W, Wu S, Cheng X, Dai H, Ross K, Du X, Yin W: Prevalence of Alzheimer's disease and other dementing disorders in an urban community of Beijing, China. Neuroepidemiology 2000, 19:194-200.

8. O'Brien JA, Caro J): Alzheimer's disease and other dementia in nursing homes: levels of management and cost. Int Psychogeriatr 2001, I 3:347-358.

9. Rovner BW, German PS, Broadhead J, Morriss RK, Brant LJ, Blaustein J, Folstein MF: The prevalence and management of dementia and other psychiatric disorders in nursing homes. Int Psychogeriatr 1990, 2:13-24.

10. Chandler JD, Chandler JE: The prevalence of neuropsychiatric disorders in a nursing home population. J Geriatr Psychiatry Neurol 1988, I:71-76.

I I. Seno H, Ishino H, Inagaki T, lijima M, Kaku K, Inata T, Hirai M: A neuropathological study of dementia in nursing homes in Shimane prefecture, Japan: evaluation of the age and gender effect. J Gerontol A Biol Sci Med Sci 1999, 54:M3 I2-314.

12. Ishino H, Seno H, Inagaki T, Naora C, lijima M, Tanaka $O$ et al.: Relative frequencies of dementia of the Alzheimer type and vascular dementia in Japanese nursing homes. Jpn J Psychiatry Neurol 1990, 44:55I-556.

13. Fleminger S, Oliver DL, Lovestone S, Rabe-Hesketh S, Giora A: Head injury as a risk factor for Alzheimer's disease: the evidence I 0 years on; a partial replication. I Neurol Neurosurg Psychiatry 2003, 74:857-62.

14. Prasad KN, Cole WC, Prasad KC: Risk factors for Alzheimer's disease: role of multiple antioxidants, non-steroidal antiinflammatory and cholinergic agents alone or in combination in prevention and treatment. J Am Coll Nutr 2002, 2I:506-22.

15. Alberca R, Montes-Latorre E, Gil-Neciga E, Mir-Rivera P, Lozano-San Martin P: Alzheimer's disease and women. Rev Neurol 2002, 35:57I-9.

16. Panza F, Solfrizzi V, D'Introno A, Capurso C, Colacicco AM, Torres F et al.: Genetics of late-onset Alzheimer's disease: vascular risk and beta-amyloid metabolism. Recenti Prog Med 2002, 93:489-97.

17. Folstein MF, Folstein SE, McHugh PR: "Mini-mental state". A practical method for grading the cognitive state of patients for the clinician. J Psychiatr Res 1975, I2:189-198.

18. Lobo A, Saz P, Marcos G, Dia JL, de la Camara C, Ventura T, Morales Aslin F, Fernando Pascual L, Montanes JA, Aznar S: Revalidation and standardization of the cognition mini-exam (first Spanish version of the Mini-Mental Status Examination) in the general geriatric population. Med Clin 1999, I I 2:767-74.

19. Kafonek S, Ettinger WH, Roca R, Kittner S, Taylor N, German PS Instruments for screening for depression and dementia in a Iong-term care facility. I Am Geriatr Soc 1989, 37:29-34

20. Tangalos EG, Smith GE, Ivnik RJ, Petersen RC, Kokmen E, Kurland LT et al: The Mini-Mental State Examination in general medical practice: clinical utility and acceptance. Mayo Clin Proc 1996, 7 I:829-37

21. Osterweil D, Mulford P, Syndulko K, Martin M: Cognitive function in old and very old residents of a residential facility: relationship to age, education, and dementia. J Am Geriatr Soc 1994, 42:766-73.

22. Bronfman M, Guiscafré $H$, Castro $V$, Castro R, Gutiérrez G: La medición de la desigualdad: una estrategia metodológica, análisis de las características socioeconómicas de la muestra. Arch Invest Med 1988, 19:351-360.

23. Pichot P, López-ibor Aliño J], Valdés Miyar M: DSM-IV. Manual diagnóstico y estadístico de los trastornos mentales Masson, SA: Barcelona; 1995.

24. Dawson B, Trapp RG: Resumen y presentación de datos en cuadros y figuras. In Bioestadística médica Manual Moderno: México; 2002:27-67.

25. Hosmer DW, Lemeshow S: Interpretation of the Coefficients of the Logistic Regression Model. In Applied Logistic Regression John Wiley \& Sons, Inc: New York; 1989:38-76.

26. Prince $M$ : Dementia in developing countries. A consensus statement from the 10/66 Dementia Research Group. Int J Geriatr Psychiatry 2000, I 5: 14-20.

27. Hux MJ, O'Brien BJ, Iskedjian M, Goeree R, Gagnon M, Gauthier S Relation between severity of Alzheimer's disease and costs of caring. CMAJ 1998, I 59:457-465.

28. Fountoulakis KN, Tsolaki M, Mohs RC, Kazis A: Epidemiological dementia index: a screening instrument for Alzheimer's dis- ease and other types of dementia suitable for use in populations with low education level. Dement Geriatr Cogn Disord 1998, 9:329-38.

29. Wang HX, Karp A, Winblad B, Fratiglioni L: Late-life engagement in social and leisure activities is associated with a decreased risk of dementia: a longitudinal study from the Kungsholmen project. Am J Epidemiol 2002, I 55: 108I-1087.

30. Mortimer JA: Brain reserve and the clinical expression of Alzheimer's disease. Geriatrics 1997, 52(Suppl 2):S50-3.

31. Gurland BJ, Wilder DE, Lantigua R, Stern Y, Chen J, Killeffer EH, Mayeux R: Rates of dementia in three ethnoracial groups. Int J Geriatr Psychiatry 1999, 14:481-493.

32. Weintraub D, Raskin A, Ruskin PE, Gruber-Baldini AL, Zimmerman SI, Hebel JR et al.: Racial differences in the prevalence of dementia among patients admitted to nursing homes. Psychiatr Serv 2000, 5 I: I259-1264

33. Li G, Shen YC, Chen CH, Zhau YW, Li SR, Lu M: A three-year follow-up study of age-related dementia in an urban area of Beijing. Acta Psychiatr Scand I99I, 83:99-104.

34. Kristjansson B, Helliwell $B$, Forbes WF, Hill GB: Marital status, dementia and institutional residence among elderly Canadians: the Canadian Study of Health and Aging. Chronic Dis Can 1999, 20:154-157.

35. Helmer C, Damon D, Letenneur L, Fabrigoule C, Barberger-Gateau $P$, Lafont $S$ et al.: Marital status and risk of Alzheimer's disease: a French population-based cohort study. Neurology 1999, 53:1953-1958.

36. Ruitenberg A, van Swieten JC, Witteman JC, Mehta KM, van Duijn CM, Hofman A, Breteler MM: Alcohol consumption and risk of dementia: the Rotterdam Study. Lancet 2002, 359:28I-286.

37. Tyas SL: Alcohol use and the risk of developing Alzheimer's disease. Alcohol Res Health 200I, 25:299-306.

38. Lindsay J, Laurin D, Verreault R, Hebert R, Helliwell B, Hill GB, McDowell I: Risk factors for Alzheimer's disease: a prospective analysis from the Canadian Study of Health and Aging. Am J Epidemiol 2002, I 56:445-453.

39. Almeida OP, Hulse GK, Lawrence D, Flicker L: Smoking as a risk factor for Alzheimer's disease: contrasting evidence from a systematic review of case-control and cohort studies. Addiction 2002, 97:15-28.

40. Holstein J, Chatellier G, Piette F, Moulias R: Prevalence of associated diseases in different types of dementia among elderly institutionalized patients: analysis of 3447 records. J Am Geriatr Soc 1994, 42:972-977.

4I. Serby M, Chou JC, Franssen EH: Dementia in an American-Chinese nursing home population. Am J Psychiatry 1987, |44:8| |-8|2.

\section{Pre-publication history}

The pre-publication history for this paper can be accessed here:

http://www.biomedcentral.com/1471-244X/4/3/prepub

Publish with Biomed Central and every scientist can read your work free of charge

"BioMed Central will be the most significant development for disseminating the results of biomedical research in our lifetime. "

Sir Paul Nurse, Cancer Research UK

Your research papers will be:

- available free of charge to the entire biomedical community

- peer reviewed and published immediately upon acceptance

- cited in PubMed and archived on PubMed Central

- yours - you keep the copyright
BioMedcentral 